\title{
A expressão da evidencialidade reportativa e da evidencialidade citativa na língua portuguesa
}

DOI: http://dx.doi.org/10.21165/el.v49i3.2641

\section{Amanda Freiberger Miranda'}

\section{Resumo}

A evidencialidade é a categoria responsável por expressar a fonte da informação veiculada em um enunciado. Nesta pesquisa, são analisadas a evidencialidade reportativa e a citativa, subtipos evidenciais que apresentam uma informação adquirida de terceiros. Estudos anteriores atestam a sistematicidade dessa categoria em línguas que a marcam gramaticalmente; interessa, então, a esta pesquisa verificar como essas subcategorias se manifestam no português, língua em que a expressão da evidencialidade é majoritariamente lexical. Para tanto, analisamos textos jornalísticos do jornal on-line Folha de São Paulo, utilizando, como ferramenta de identificação das categorias, a descrição dos evidenciais feita pela Gramática Discursivo-Funcional, que viabiliza a descrição dos fenômenos linguísticos a partir da consideração de uma ordem hierárquica dos níveis de organização do enunciado, em que a pragmática exerce determinações sobre todos os demais níveis.

Palavras-chave: evidencialidade reportativa; evidencialidade citativa; Gramática Discursivo-Funcional.

1 Universidade Estadual Paulista "Júlio de Mesquita Filho" (UNESP), São José do Rio Preto, São Paulo, Brasil; amandafreibergerm@gmail.com; https://orcid.org/0000-0003-4495-4159 


\title{
The Expression of Reportative and Quotative Evidentiality in Portuguese
}

\begin{abstract}
Evidentiality is the category responsible for expressing the source of the information conveyed in a statement. In this research, we will analyze the reportative and the quotative evidentiality, evidential subtypes that present information acquired from third parties. This category's systematicity in grammar-marking languages is already attested, thus, it is of our interest to verify how these subcategories manifest in Portuguese, a language in which the expression of evidentiality is mostly lexical. To that, we will analyze texts of the online newspaper Folha de São Paulo, using, as a way of identifying the evidentials, the description made by the Functional Discourse Grammar, which enables the description of linguistic phenomena from the consideration of a hierarchical order of the levels of organization of the utterance, in which pragmatics exercises determinations on all other levels.
\end{abstract}

Keywords: reportative evidentiality; quotative evidentiality; Functional Discourse Grammar.

\section{Introdução e justificativa}

A evidencialidade é a categoria responsável por expressar a fonte da informação veiculada no enunciado, podendo ser expressa gramaticalmente ou lexicalmente nas diferentes línguas. Na língua portuguesa, a evidencialidade é expressa majoritariamente pela forma lexical. De acordo com Aikhenvald (2004), em um dos trabalhos fundamentais sobre a evidencialidade, a função da categoria é a de explicitar como o falante adquiriu uma informação e como caracteriza a origem do conhecimento que está expressando.

O estudo da categoria evidencial é considerado recente, isso porque, como não é marcada gramaticalmente na maioria das línguas europeias, a evidencialidade só passou a receber mais atenção após análise de línguas consideradas "exóticas" que marcam a categoria gramaticalmente e facilitam sua percepção e avaliação de sua sistematicidade. Em seu livro, Aikhenvald (2004) analisa a forma e a função dessa categoria em mais de 500 línguas de diferentes regiões do mundo, todas com marcação gramatical. Em muitas dessas línguas, uma vez que a fonte da informação precisa ser obrigatoriamente expressa no enunciado, enunciados que não a expressam são considerados agramaticais.

Uma declaração que não explicita a fonte da informação pode ser vista com suspeita e falta de credibilidade, e é justamente em cima desse efeito de sentido que esta pesquisa se baseia. Pretende-se, aqui, investigar dois tipos específicos de evidenciais: o reportativo 
e o citativo, subtipos que marcam que a fonte da informação é outro falante. Pretendemos identificar os usos dessas subcategorias, em textos jornalísticos, e avaliar os efeitos de sentidos gerados a partir dos diferentes usos.

A evidencialidade é dividida de diferentes formas por diferentes autores. Uma das propostas mais relevantes é a apresentada por Willet (1988), que separou a categoria em evidencialidade direta e indireta. Por meio da evidencialidade direta, o enunciador se declara fonte do saber transmitido, enquanto por meio da evidencialidade indireta, o enunciador chega à informação transmitida por inferência (evidencialidade inferida) ou por relato de uma terceira fonte (evidencialidade relatada). $\mathrm{O}$ autor ainda subdividiu a evidência indireta relatada em evidência de segunda mão, quando a informação foi relatada por uma testemunha direta; evidência de terceira mão, quando a informação não foi relatada por uma testemunha direta, podendo ser um boato; e o mito, que pode ser entendido como uma informação que está no domínio público, uma história consagrada.

A partir dessa tipologia e de dados encontrados em discursos políticos e textos científicos, Dall'Aglio-Hattnher (2001) identificou os seguintes subtipos de evidencialidade relatada na língua portuguesa: definida, indefinida e de domínio comum. Nessa distinção, a evidencialidade relatada com fonte definida ocorre quando há uma informação de segunda mão, e a fonte dessa informação é explicitada na fala; a evidencialidade relatada de fonte indefinida apresenta uma informação de terceira mão, e o falante não especifica exatamente quem é a fonte daquela informação, esse subtipo é identificado principalmente em casos em que há indeterminação do sujeito pela terceira pessoa do plural ou pelo pronome se; por fim, a evidencialidade assumida como de domínio comum aparece quando a fonte da informação é um saber comum, sendo o verbo saber bastante utilizado para marcar esse subtipo evidencial.

Essa subdivisão da evidencialidade relatada não foi tratada na proposta de reclassificação feita por Hengeveld e Dall'Aglio-Hattnher (2015), em que, utilizando o aparato teórico da Gramática Discursivo-Funcional (GDF - HENGEVELD; MACKENZIE, 2008), definiram quatro subtipos a partir do escopo dos itens evidenciais: evidencialidade reportativa, inferência, dedução e percepção de evento. Nessa proposta, a distinção essencial deixa de ser a diferença entre evidencialidade direta e indireta e passa a ser a distinção entre o nível de organização do enunciado em que a evidencialidade se aloja, no Interpessoal (pragmático) ou no Representacional (semântico), estando a reportatividade alojada no Interpessoal e os demais subtipos, no Representacional.

Segundo Hengeveld e Dall'Aglio-Hattnher (2015), as marcações de reportatividade indicam que a informação transmitida foi originalmente produzida por outro enunciador que não o falante. A informação foi escutada ou lida e provém de outro enunciador, e não de uma dedução, inferência ou percepção de evento realizada pelo enunciador. 
A evidencialidade reportativa é o tipo de evidencialidade mais comumente encontrado nas línguas (AIKHENVALD, 2004; DE HAAN, 1999). Por essa razão, tem sido uma categoria amplamente estudada nas línguas em que sua expressão é gramatical. Sendo assim, um primeiro questionamento direciona esta pesquisa: assim como ocorre nas línguas com expressão gramatical da evidencialidade, a indicação lexical da fonte da informação é sistemática e regular a ponto de constituir uma categoria qualificacional, assim como modalidade e tempo, por exemplo?

Essa discussão origina-se do posicionamento assumido por Aikhenvald (2004), que considera a expressão do que se tem "vagamente" chamado de evidencialidade lexical como um tipo de "estratégia evidencial", dada a sua assistematicidade. Squartini (2008), utilizando evidenciais da língua francesa e italiana, também se propôs a verificar a relevância da evidencialidade lexical, comparando usos lexicais com o que se conhece sobre a evidencialidade gramatical. Entretanto, diferentemente do que propomos, o autor focou sua análise nos evidenciais inferenciais e concluiu que a expressão lexical vai além de "estratégias evidenciais" e seu estudo é pertinente para o melhor entendimento da categoria da evidencialidade.

No que se refere ao evidencial reportativo, em línguas com marcação gramatical, Aikhenvald (2004) distingue dois tipos de evidencialidade com fonte da informação diferente do autor do enunciado: a relatada (reported), que não especifica o autor do enunciado relatado, apenas aponta que foi dito por outra pessoa, e a citativa (quotative), que explicita o autor do enunciado citado. Essa mesma distinção é utilizada por muitos autores, inclusive por Hengeveld e Mackenzie (2008); entretanto, novos estudos sobre o assunto atualizaram essa distinção na GDF.

Em trabalho recente, Hengeveld e Fischer (2018), após analisarem as categorias de tempo, modalidade e evidencialidade na língua A'ingae, também separam os casos em reportativo e citativo, entretanto, propõem uma leitura diferente das duas subcategorias. O subtipo reportativo identificado por Hengeveld e Dall'Aglio-Hattnher (2015) passa, então, a ser subdividido em reportatividade e citação. Nessa nova leitura, a reportatividade é a subcategoria responsável por indicar que a fonte da informação é outro falante, mas o enunciado é proferido com as palavras do enunciador, com adaptações nos tempos verbais e nos elementos dêiticos, enquanto a citação é a tentativa de uma repetição exata do enunciado do enunciador-fonte. No português, essa diferença fica clara na separação dos casos de discurso direto, citativo, e discurso indireto, reportativo. Na GDF, é possível identificar essas diferenças observando em qual camada os dois subtipos estão alocados, a citação, na camada do Ato Discursivo, e a reportatividade, na camada do Conteúdo Comunicado ou do Subato Atributivo.

Nossa hipótese é a de que a expressão lexical da evidencialidade em língua portuguesa obedece a padrões morfossintáticos que nos permitem identificar os mesmos subtipos 
de reportatividade e citação apontados por Aikhenvald (2004) e Hengeveld e Fischer (2018) para a evidencialidade de expressão gramatical.

Para comprovar essa hipótese, investigaremos as formas de expressão lexical da evidencialidade reportativa e citativa, utilizando como ferramenta de identificação das categorias a Gramática Discursivo-Funcional, nos moldes dos estudos desenvolvidos por Hengeveld e Dall'Aglio-Hattnher (2015) e Hengeveld e Fischer (2018) para as línguas com expressão gramatical.

As subcategorias denominadas como reportativo e citativo são identificadas por diferentes autores (WILLET, 1988; DE HAAN, 1999; CORNILLIE, 2007; AIKHENVALD, 2004). As diferentes nomenclaturas que são atribuídas a essas subcategorias evidenciam critérios classificatórios que envolvem tanto o tipo de fonte de informação como o modo como a informação foi obtida: rumor, folclore, evidencialidade relatada, de segunda mão, de terceira mão ou citativa. Todos esses subtipos são considerados casos de reportatividade ou citação na GDF, dependendo da camada em que estão alojados.

Um dos argumentos para justificar a pertinência do estudo da expressão lexical da evidencialidade reportativa e citativa pode ser identificado em um uso bastante corriqueiro no discurso jornalístico, em que um conteúdo comunicado é atribuído a uma fonte, como é típico da reportatividade, embora essa fonte não seja definida, como se vê nas seguintes ocorrências:

(1) Cientistas dizem estar mais perto da cura do resfriado. (FSP - Equilíbrio e Saúde)

(2) Especialistas dizem que o distritão irá favorecer políticos mais conhecidos e com mais recursos para fazer campanha. (FSP - Poder)

Nesses casos, apenas a estrutura reportativa é responsável por emprestar credibilidade ou descomprometimento para o enunciador, uma vez que, semanticamente, não há indicação de quem é essa fonte. Ou seja, tanto o falante como o ouvinte identificam uma estrutura lexical evidencial, em que um SN ocupa o lugar da fonte, e os efeitos de sentido dela decorrentes, mesmo quando esse SN é indefinido e remete a uma fonte absolutamente vaga, como nos exemplos acima. Usos como esses demonstram a relevância da indicação da evidencialidade na construção da argumentação. Mais ainda, esses usos demonstram que a expressão lexical da evidencialidade é recorrente em língua portuguesa, a ponto de ter sua estrutura percebida pelos interlocutores como estratégia argumentativa.

Outro aspecto que merece investigação são os diferentes efeitos de sentido decorrentes do uso da evidencialidade reportativa (3) e da evidencialidade citativa (4), comprovando a relevância dessa nova classificação para línguas com marcação lexical: 
(3) A Ponto Final afirma que o ex-governador Sérgio Cabral (PMDB) recebeu do setor de transportes R\$144,7 milhões entre 2010 e 2016. (FSP - Poder)

(4) "Médicos usavam esse tipo de medicação com resultados muito bons", afirma Halpern. (FSP - Equilibrio e Saúde)

Essas diferenças já foram analisadas do ponto de vista estritamente pragmático por Fossey (2006), em sua dissertação de mestrado, em que a autora, utilizando como aparato teórico a Análise do Discurso francesa, estuda a forma como é feita a divulgação científica nas revistas Pesquisa Fapesp e Superinteressante, e, nessa análise, identifica as diferentes formas de emergência do que ela chama de discurso relatado.

Acreditando que a sistematicidade desses usos permite a identificação de subtipos evidenciais em língua portuguesa, e que a intencionalidade pragmática determina as estruturas dos enunciados, em consonância com os pressupostos da GDF, interessa a esta pesquisa investigar quais são as características semânticas e morfossintáticas da evidencialidade reportativa ${ }^{2}$ e da citativa (tempo absoluto ou relativo, modo da oração encaixada, natureza semântica do verbo encaixador, posição da estrutura evidencial, natureza definida ou indefinida da pessoa, entre outras) e em que medida essas estruturas revelam o grau de comprometimento do autor.

Tendo em vista a diversidade de formas encontradas em uma investigação preliminar das ocorrências no córpus, buscamos responder à seguinte questão: os diferentes subtipos de evidencialidade reportativa e citativa que aparecem na literatura de línguas com marcação gramatical são pragmática, semântica ou morfossintaticamente relevantes para línguas com expressão lexical da evidencialidade?

Para identificar a especificidade da expressão lexical desses subtipos evidenciais, temos, ainda, os seguintes objetivos específicos: analisar as diferenças pragmáticas, semânticas e morfossintáticas entre a evidencialidade reportativa e a evidencialidade citativa; e analisar os efeitos de sentido decorrentes da indicação de fonte definida ou dos tipos de fonte indefinida na expressão de um conteúdo reportado.

\section{Material e métodos}

O uso da evidencialidade não é obrigatório em línguas que marcam a categoria lexicalmente, mas, aindaassim, faz-se necessário em determinados contextos específicos. Um exemplo disso é o texto jornalístico, contexto no qual evidenciais, especialmente

2 Utilizando o mesmo arcabouço teórico, os evidenciais reportativos já foram analisados por Rendón (2006) que, contudo, descreveu a língua Ecuadorian Quechua, que tem expressão gramatical da evidencialidade. 
reportativos e citativos, aparecem com grande recorrência, uma vez que se busca passar uma informação que seja entendida como confiável, sendo o evidencial uma importante estratégia para empregar essa confiabilidade; além de ser uma forma de o falante se descomprometer com determinadas informações. Por essa razão, o discurso jornalístico foi escolhido para a constituição do córpus dessa pesquisa.

A composição desse córpus e os critérios utilizados para analisar as ocorrências são detalhados nos subitens a seguir.

\section{Composição do córpus}

Como material para a realização deste estudo, utilizamos um córpus composto por textos da seção de política, Poder, da seção de ciência, Equilíbrio e Saúde, e da seção opinativa, Colunas, do jornal on-line Folha de São Paulo. Os textos analisados são publicações escolhidas aleatoriamente do mês de agosto de 2017. Os textos foram coletados no website do jornal, utilizando o filtro de pesquisa de datas, o que permitiu a equiparação entre as amostras das diferentes seções, totalizando $80 \mathrm{~KB}$ de textos de cada tipo. A escolha desses três tipos de texto foi motivada pela hipótese de que textos com caráter mais científico tendem a apresentar mais citações literais, com a reprodução direta do conteúdo comunicado pela fonte da informação e com indicação da fonte definida, com o intuito de dar mais credibilidade ao que é relatado, além de evitar comprometimento com o que é dito, especialmente por se tratar de questões de saúde, que podem gerar problemas aos leitores diretamente ligados às matérias publicadas. Já os textos sobre política tendem a apresentar marcações variadas de evidencialidade reportativa por sempre apresentarem o que os políticos dizem, sem a necessidade de tentar reproduzir exatamente o que foi dito como nos textos científicos. Os textos da seção Colunas, por sua vez, foram utilizados por se tratarem de textos em que, espera-se, a argumentação não dependa da indicação exata da fonte da informação, como em Poder e Equilíbrio e Saúde, pois são textos em que o enunciador expressa a sua própria opinião. As ocorrências abaixo ilustram, respectivamente, esses três casos:

(5) O ministro da Casa Civil, Eliseu Padilha, afirmou que faz viagens em avião da FAB por motivos de segurança (FSP - Poder)

(6) "Alguns estudos mostram que no início alguns pacientes experimentam um aumento dos níveis de colesterol, e que vem uma queda nos meses seguintes", afirma Campos. (FSP - Equilíbrio e Saúde)

(7) Dizem os entendidos que derrotas ensinam mais que vitórias. (FSP - Colunas) 


\section{Critérios de análise}

Os dados são analisados a partir de critérios morfossintáticos, semânticos e pragmáticos. Os critérios morfossintáticos têm como objetivo identificar quais as formas de ocorrência da reportatividade e da citação no português, língua que marca essas subcategorias lexicalmente. Para tanto, analisamos a forma de expressão do reportativo e do citativo; nos casos expressos por verbo, o tempo e o modo do item evidencial; e o tempo e modo do verbo da oração encaixada, nos casos em que o conteúdo reportado é uma oração.

O primeiro critério visa identificar quais as formas de expressão do reportativo e do citativo, que variaram nas formas de verbo, como em (8), e conectivos, como em (9):

(8) Alguns dizem que foi a corrupção de uma natureza humana que vivia em eterno equilíbrio no campo. (FSP - Colunas)

(9) Segundo Edmundo Klotz, presidente da Abia, devem fazer parte da lista biscoitos, bolos, lácteos e refrigerantes. (FSP - Equilíbrio e Saúde)

O critério seguinte é utilizado nos casos em que o item evidencial é um verbo; trata-se da identificação do tempo e modo desse verbo. Objetivamos, com isso, verificar se há correlação entre o tempo e o modo do verbo evidencial e do verbo da oração reportada, bem como analisar os efeitos de sentido decorrentes.

Como último critério morfossintático, identificamos o tipo de conteúdo reportado, se é composto por um sintagma nominal (10), por uma oração ou mais (11), ou por elementos vicários, como os advérbios sim e não (12). Esse critério visa investigar se a configuração morfossintática do conteúdo reportado interfere na adesão ou não do enunciador a esse conteúdo.

(10) No ano passado, viajou 12 vezes alegando motivo de segurança e, em apenas dois deslocamentos, foi detalhado compromisso oficial, como para uma palestra sobre a reforma previdenciária. (FSP - Poder)

(11) "A reforma política não parece a melhor. O texto aprovou como permanentes questões que deveriam ser transitórias. O texto original era para que o fundo fosse reduzido ao longo do tempo. A sociedade não concorda com esse valor alto. Como permanente, acho muito grave", disse Maia, em seminário da FGV, no Rio. (FSP - Poder)

(12) Pennebaker disse que, em média, um a cada 20 alunos acabou chorando, mas, quando questionados se queriam continuar o experimento, sempre disseram que sim. (FSP Equilíbrio e Saúde) 
Na análise semântica, nos casos em que o item evidencial é expresso por um verbo, identificamos os diferentes tipos de verbos de elocução e os classificamos de acordo com a intenção expressa em cada um. Para elaboração desse critério, utilizamos como base a classificação dos verbos de elocução feita por Martins (1989). Os verbos de elocução foram separados nas seguintes categorias: verbos de elocução propriamente ditos ou que, pela polissemia, funcionam como elocutivos; verbos com que o enunciador (doravante $\mathrm{E}$ ) indica que o enunciador-fonte (doravante $\mathrm{E}_{\mathrm{f}}$ ) proferiu o enunciado de função apelativa, esperando uma reação do ouvinte; verbos com que o E não quis afirmar um fato, mas apenas levantar uma suposição, uma suspeita; e verbos que indicam que o enunciador considera o enunciado do enunciador-fonte como verdadeiro ou falso. Acrescentamos a esses tipos o verbo de negação, entendendo que funciona como 'dizer + não', a seguir apresentamos um quadro com os tipos de verbos e alguns exemplos de cada um:

Quadro 1. Tipos de verbos de elocução

\begin{tabular}{|l|l|l|l|l|}
\hline $\begin{array}{l}\text { Verbos de elocução } \\
\text { propriamente } \\
\text { ditos ou que, } \\
\text { pela polissemia, } \\
\text { funcionam como } \\
\text { elocutivos }\end{array}$ & $\begin{array}{l}\text { o Eindica que } \\
\text { o Ef proferiu o } \\
\text { enunciado de } \\
\text { função apelativa }\end{array}$ & $\begin{array}{l}\text { Verbos com que o } \\
\text { Enão quis afirmar } \\
\text { um fato, mas } \\
\text { apenas levantar } \\
\text { uma suposição, } \\
\text { uma suspeita }\end{array}$ & $\begin{array}{l}\text { Verbos que } \\
\text { indicam que E } \\
\text { considera o } \\
\text { enunciado como } \\
\text { verdadeiro ou falso }\end{array}$ & $\begin{array}{l}\text { Verbos de } \\
\text { negação }\end{array}$ \\
\hline $\begin{array}{l}\text { Dizer, declarar, } \\
\text { descrever, insinuar }\end{array}$ & $\begin{array}{l}\text { Perguntar, } \\
\text { interrogar, pedir, } \\
\text { reclamar }\end{array}$ & $\begin{array}{l}\text { Insinuar, sugerir, } \\
\text { dar a entender, } \\
\text { acreditar }\end{array}$ & $\begin{array}{l}\text { Confessar, mentir, } \\
\text { revelar, reconhecer }\end{array}$ & Negar \\
\hline
\end{tabular}

Fonte: Elaboração própria

O primeiro critério pragmático analisado é o tipo de texto; uma vez que escolhemos três seções diferentes do jornal Folha de São Paulo, interessa-nos identificar as diferentes motivações em cada tipo de texto, Poder, Equilíbrio e Saúde e Colunas. Em seguida, identificamos o subtipo evidencial, reportativo ou citativo, e analisamos seu uso em cada seção. Pretendemos relacionar o tipo de texto a todos os demais critérios, a fim de descobrir a especificidade de uso de cada um.

Além disso, na análise pragmática, verificamos as diferentes formas de reportar um conteúdo, por meio de discurso direto (13), indireto (14) ou misto (15), que são os casos em que a reportatividade é expressa por meio de discurso indireto, com apenas um trecho marcado literalmente com o uso de aspas. Esse critério está diretamente ligado ao subtipo evidencial e foi escolhido a fim de identificar a relevância de cada tipo de discurso nos diferentes tipos de textos; acredita-se que os casos com transcrição literal do conteúdo reportado costumam ser utilizados quando se busca maior credibilidade ou maior distanciamento. 
(13) "O tumor encontra um jeito de resistir à quimioterapia, e nós estamos interessados em descobrir de que forma isso acontece", diz a Clarissa Ribeiro Reily Rocha, doutora pela USP e pesquisadora do MIT (Instituto de Tecnologia de Massachusetts). (FSP Equilíbrio e Saúde)

(14) A empresa divulgou uma nota dizendo que já iniciou o processo de recolhimento voluntário do medicamento. (FSP - Equilíbrio e Saúde)

(15) Em rápido contato com a Folha na saída do prédio, o empresário disse que estava "fazendo uma visita" ao procurador, que não via desde o processo de delação premiada. (FSP - Poder)

O próximo critério pragmático busca investigar o papel da (in)determinação da fonte da informação reportada na construção da argumentação e teve como base a classificação proposta por Teixeira (2014), que analisou os tipos de indeterminação do sujeito de acordo com os preceitos da GDF. A autora utiliza os operadores de identificabilidade [ $\pm i d]$ e de especificidade [ $\pm s]$, que podem se combinar das seguintes formas: [+id, $+s]$, [+id, -s], [-id, +s], e [-id, -s]. De acordo com a GDF, esses operadores podem ser aplicados a qualquer referente tido como identificável para o falante e para o ouvinte.

A combinação [+id, +s], que trata de um item identificável tanto para o emissor quanto para o destinatário, é esperada como sendo o tipo mais recorrente de determinação de fonte da informação, uma vez que é o tipo que mais empresta credibilidade a um enunciado. Nos casos em que ocorrem [+id, -s] ou [-id, +s], a determinação é parcial, apenas um dos interlocutores reconhece o referente. Tendo isso em vista, a indeterminação do sujeito pode ser parcial do tipo 1 [+d; -s], parcial do tipo 2 [-id; +s], ou ser uma indeterminação total, do tipo $3[-i d,-s]$.

O tipo 1 de indeterminação diz respeito a um referente que não é conhecido pelo emissor, mas que se pressupõe que é conhecido pelo receptor. É um tipo comum encontrado em entrevistas, quando se faz uma pergunta. 0 tipo 2 de indeterminação, por outro lado, apresenta um referente conhecido para o emissor, mas desconhecido para o receptor. Já o tipo 3 apresenta um referente desconhecido tanto para o emissor quanto para o receptor.

Essas classificações são aplicadas a Subatos, que apresentam os traços de identificabilidade e especificidade. Entretanto, na análise, além de haver ocorrências indeterminadas como ocorre com o tipo 3, encontramos ocorrências em que há uma indeterminação marcada pela desinência verbal, não se tratando de um Subato, não apresentando, então, os traços de [tid] e [ \pm s]. Por essa razão, chamamos, na análise, esses casos de "fonte indefinida" juntamente com as ocorrências do tipo 3, pois não nos interessa de que forma a indeterminação é marcada, interessa-nos apenas mostrar que o evidencial foi usado sem uma fonte definida, seja essa indefinição marcada por um Subato genérico ou não. 
Como último critério, identificamos em qual camada da GDF o conteúdo reportado se encontra. De acordo com Hengeveld e Fischer (2018), o reportativo modifica um Conteúdo Comunicado (C), exemplo (16), ou um Subato de Atribuição (T), exemplo (17) e o citativo modifica um Ato Discursivo (A) (18). Visamos verificar se é possível a reportatividade modificar outras camadas do Nível Interpessoal.

(16) Nos bastidores do Supremo, Fachin já disse que é possível devolver um acordo para eventualmente ajustar alguma cláusula. (FSP - Poder)

(17) Na última sexta-feira (18), Gilmar classificou como "atípico" o fato de Bretas ter expedido novos mandados de prisão preventiva contra o empresário Jacob Barata Filho (FSP Poder)

(18) "Quanto mais precocemente indicar a cirurgia, com menor tempo de uso de insulina, melhores os resultados", diz [Ricardo Cohen]. (ES)

Para testar a aplicabilidade e adequação dos critérios de análise a que serão submetidos todos os dados em etapa posterior, foram selecionadas as 20 primeiras ocorrências de cada tipo de texto, essa análise é apresentada na próxima seção.

\section{Discussão e análise}

No córpus total, foram encontrados 638 casos de reportatividade e citação assim distribuídos:

Tabela 1. Total de ocorrências de reportativos e citativos no córpus

\begin{tabular}{c|c|c|c|c}
\hline Seção & Poder & Equilíbrio e Saúde & Colunas & TOTAL \\
\hline Ocorrências & 260 & 230 & 148 & 638 \\
\hline
\end{tabular}

Fonte: Elaboração própria

A diferença quantitativa no uso dos evidenciais pode, em princípio, ser explicada pelo fato de que, no texto mais opinativo da seção Colunas, a marcação da fonte para validação de uma informação não se faz tão necessária, uma vez que, em um texto opinativo, o falante costuma ser a fonte do que é expresso. Vale mencionar que, apesar do número mais baixo de reportatividade e citação nessa seção, as categorias são expressas, em grande parte, quando a matéria aborda assuntos sobre política, tema central da seção Poder, seção que mais utiliza a marcação da fonte da informação. A discussão dessas diferenças, no entanto, será feita quando tivermos a análise de todas as ocorrências. Por ora, faremos apenas uma pré-análise de um recorte do córpus (60 ocorrências, 20 de cada seção) para verificar a validade dos critérios de análise selecionados. 
Como é comum nas línguas que marcam a evidencialidade lexicalmente, a forma de expressão preferida para marcar a reportatividade e a citação é por meio de um verbo (19), utilizado em $90 \%$ dos casos, sendo o conectivo (20) a forma menos utilizada, apenas em $10 \%$ dos casos.

(19) Alguns dizem que foi a corrupção de uma natureza humana que vivia em eterno equilíbrio no campo. (FSP - Colunas)

(20) Por essa razão, segundo ele, o acordo estaria longe de ser fechado. (FSP - Poder)

Ao observarmos os usos dessas formas de expressão em cada seção, notamos que a seção Poder foi a que mais recorreu a essa forma menos usual de expressar a reportatividade e a citação, enquanto a seção Colunas apresenta somente um caso de conectivo e a seção Equilíbrio e Saúde faz uso apenas de verbos, forma mais comum de expressão da categoria. Essa diferença pode ser observada na tabela a seguir:

Tabela 2. Tipo de reportativo e citativo

\begin{tabular}{c|c|c|c}
\hline & Verbo & Conectivo & TOTAL \\
\hline PODER & $15-75 \%$ & $5-25 \%$ & $20-100 \%$ \\
\hline EQ. E SAÚDE & $20-100 \%$ & $0-0 \%$ & $20-100 \%$ \\
\hline COLUNAS & $19-95 \%$ & $1-5 \%$ & $20-100 \%$ \\
\hline TOTAL & $54-90 \%$ & $6-10 \%$ & $60-100 \%$ \\
\hline
\end{tabular}

Fonte: Elaboração própria

A semântica dos verbos utilizados nas 54 ocorrências, em que a reportatividade e a citação foram expressas por um verbo, foi analisada com o intuito de verificar o tipo de verbo utilizado, como explicado na seção anterior. Os verbos dicendi propriamente ditos ou que funcionam como dicendi foram a maioria (21), somando 52 ocorrências (96,30\%). Foi encontrado apenas um caso de verbo que indica tanto a posição do Eem relação ao $\mathrm{E}_{f}$ quanto certeza da verdade ou não do enunciado (22), e um caso de verbo em que E marca que $E_{f}$ proferiu um enunciado de função apelativa, em que recomendava ou sugeria uma ação (23), por exemplo.

(21) Questionado sobre o conteúdo, Funaro disse que não poderia comentar. (FSP - Poder)

(22) Como explicar que uma forma venezuelana do vírus acabou matando pessoas em Minas, no Rio e no Espírito Santo? Essa é outra pergunta em aberto, reconhece Bello. (FSP - Equilíbrio e Saúde) 
(23) Agora, uma pesquisa recente da Nova Zelândia sugeriu que não é necessário realizar a escrita antes de você se machucar. (FSP - Equilíbrio e Saúde)

Os diferentes tipos de verbos empregados podem indicar maior ou menor comprometimento do enunciador com a fala do enunciador-fonte. Em (21), por exemplo, o grau de comprometimento é mais neutro do que em (22), em que o uso do verbo "reconhecer" denota uma concordância do enunciador com o conteúdo reportado em questão.

Uma análise mais detalhada desses verbos evidenciais mostra que o tempo e modo mais empregados foram o presente $(61,11 \%)$ e o indicativo (100\%), seguido pelo pretérito perfeito $(35,19 \%)$ e pretérito imperfeito $(3,70 \%)$. O presente foi o tempo mais utilizado. Isso se deve ao fato de o presente poder marcar, além de um fato/ação que ocorre no momento da fala, uma verdade permanente, sendo mais assertivo do que os outros tempos verbais no processo de argumentação. $\mathrm{O}$ uso do pretérito perfeito também já era esperado: uma vez que não se pode reportar algo que não foi falado ainda, a reportatividade e a citação sempre se referem a um enunciado emitido anteriormente, seja em um passado recente ou remoto.

Verificou-se um maior número de verbos no presente em Equilíbrio e Saúde, enquanto a seção Poder recorre mais à marcação no passado. Isso se deve ao tipo de informação transmitida em cada um desses textos. Em Equilíbrio e Saúde, é recorrente a utilização da categoria para tratar de assuntos médicos, indicações de cuidados com a saúde e o meio ambiente, e, normalmente, esses fatos são verdades permanentes, como no exemplo (24). Já em Poder, seção composta por textos que abordam a política, o uso mais recorrente é a transmissão da fala de políticos. Essas falas são mostradas muitas vezes como pontuais, como no exemplo (25); não se trata de verdades absolutas ou de informações que são entendidas como permanentes, mas, na maioria dos casos, a reportatividade marca o que $\mathrm{E}_{\mathrm{f}}$ disse em um momento determinado do passado, por uma razão específica:

(24) A homeopatia também não encontra respaldo. "Pode servir para outras coisas, mas não para tratar a obesidade", afirma Cintia Cercato. (FSP - Equilíbrio e Saúde)

(25) Ao sair, escoltado, o corretor foi abordado por jornalistas que perguntaram se ainda tem o que entregar aos procuradores envolvendo o presidente. "Ainda tem", respondeu, ao entrar no elevador do prédio da Justiça Federal. (FSP - Poder)

A baixa incidência de pretérito imperfeito nesse tipo de texto era esperada, uma vez que se trata de textos que têm como objetivo transmitir um conhecimento, uma informação, função pouco relacionada com o tempo pretérito imperfeito, que indica uma ação que ocorria no passado, e tinha uma duração ou repetição. Sendo assim, é lógico que os 
únicos casos de reportativo marcados no tempo pretérito imperfeito estejam na seção Colunas, uma vez que essa seção é a mais opinativa e mais suscetível a uma linguagem menos formal com conteúdo menos informativo do que as outras seções analisadas, como se vê no exemplo (26):

(26) Quando navegava na própria arrogância, Eike dizia que emprestava seu avião a Cabral e ninguém tinha nada a ver com isso. (FSP - Colunas)

Em todos os casos analisados até o momento, o conteúdo reportado é manifesto na forma de uma oração. Verificamos no córpus completo que há outras formas de expressão do conteúdo reportado e, por essa razão, manteremos esse critério, porém essas diferentes formas de expressão não apareceram no recorte das 20 primeiras ocorrências de cada seção.

Assim como o tempo mais utilizado nos verbos reportativos e citativos foi o presente, as orações reportadas também recorreram mais à utilização desse tempo verbal. Entretanto, os tempos utilizados nessas orações foram mais variados do que os tempos dos verbos reportativos e citativos, uma vez que um enunciado reportado pode aparecer em qualquer tempo e modo verbal, podendo inclusive ser uma previsão sobre o futuro, diferentemente do verbo reportativo e do citativo que só podem ser usados no presente ou no passado. Nessa primeira análise, ainda não foi possível estabelecer uma relação sistemática entre os tempos dos verbos evidenciais e os verbos das orações reportadas; manteremos esse critério a fim de identificar essa sistematicidade no córpus completo.

O modo mais utilizado nessas orações foi o indicativo, que expressa uma assertividade maior do que o subjuntivo. Encontramos apenas um caso de subjuntivo na seção Colunas. A ausência de imperativo pode ser explicada pelo tipo de texto, que visa transmitir informação e não dar ordens. As formas nominais também foram pouco utilizadas; até o momento identificamos apenas um caso de infınitivo na seção Poder (27):

Doria, por exemplo, já defendeu mudanças no sistema previdenciário. Em abril, disse à revista "Época" ser contra descriminalizar a interrupção da gravidez, fora "casos de mulheres estupradas", exceção já contemplada pela lei. (FSP - Poder)

Como primeiro critério pragmático, identificamos o subtipo evidencial em cada seção, como mostra a tabela a seguir: 
Tabela 3. Subtipo evidencial

\begin{tabular}{c|c|c|c}
\hline & CITATIVO & REPORTATIVO & TOTAL \\
\hline PODER & $6-30 \%$ & $14-70 \%$ & $20-100 \%$ \\
\hline EQ. E SAÚDE & $15-75 \%$ & $5-25 \%$ & $20-100 \%$ \\
\hline COLUNAS & $11-55 \%$ & $9-45 \%$ & $20-100 \%$ \\
\hline TOTAL & $53,33 \%$ & $28-46,67 \%$ & $60-100 \%$ \\
\hline
\end{tabular}

Fonte: Elaboração própria

A análise do subtipo evidencial está diretamente ligada ao tipo de discurso. Visto que o discurso direto, citativo, é o tipo que mais expressa credibilidade, pois apresenta uma tentativa de reprodução exata do enunciado do $E_{f}$ essa foi a forma de expressão mais utilizada, especialmente em Equilíbrio e Saúde, que apresenta textos com assuntos mais científicos relacionados à saúde e ao meio ambiente. Uma má interpretação de uma recomendação para saúde pública, por exemplo, poderia resultar em problemas diretos para o leitor. Sendo assim, esse foi o tipo de texto que mais recorreu à transcrição literal do conteúdo reportado, como no exemplo (28):

(28) "Entendemos que o modelo possui pontos positivos, pois foca-se no risco nutricional do alimento ao enfatizar o elevado conteúdo de nutrientes negativos associados ao desenvolvimento de doenças crônicas", informa a Anvisa, que ainda estuda modelos de diferentes países antes de elaborar uma proposta. (FSP - Equilíbrio e Saúde)

O reportativo, expresso pelo discurso indireto, foi preferido em Poder, seção que mais recorre ao uso desses subtipos evidenciais, podendo ser uma das razões a escolha desse recurso a possibilidade de o discurso indireto dar mais fluência ao texto, diferentemente do discurso direto. E, como não se trata de informações científicas, o enunciador tem mais liberdade para adaptar o discurso para suas palavras, como em (29):

(29) Em nota, o ministério afirmou ainda que, como Meirelles mora em Brasília, os voos para São Paulo não podem ser contabilizados como retorno à residência do ministro. (FSP - Poder)

Além dos casos de discurso indireto, nas ocorrências de reportatividade, identificamos o uso do discurso misto, recurso menos empregado, que aparece nos casos em que o enunciador quer se descomprometer ainda mais com um trecho específico do conteúdo reportado, como no exemplo (30): 
(30) Com a regra em vigor, ele diz que os partidos são forçados a lançar dezenas de candidatos sem votos, "que não sabem nem fazer prestação de contas". (FSP - Colunas)

As ocorrências de citativo estão todas alojadas na camada do Ato Discursivo, única camada em que esse subtipo aparece. Embora o reportativo possa aparecer em diferentes camadas do Nível Interpessoal, nesta primeira análise, só foram encontrados casos do reportativo alojado na camada do Conteúdo Comunicado.

Ainda na análise pragmática, identificamos os tipos de fonte mais utilizados. A fonte definida $[+i d,+s]$ foi a forma mais empregada, uma vez que, na maioria das vezes que se usa reportativo ou citativo no texto jornalístico, a intenção é dar credibilidade à mensagem e não colocá-la como genérica e indeterminada. As porcentagens apontam que, em $91,67 \%$ dos casos, foi empregada a fonte definida (31), apenas em 6,67\% foi empregado o tipo $2[-i d,+s]$ de indeterminação (32) e em 1,66\% dos casos, fonte indefinida (33). Como esperado, o único caso com fonte indefinida apareceu na seção opinativa, uma vez que é a única seção em que não se faz necessário o apoio em uma fonte específica para validar a credibilidade do texto.

(31) "A discussão não é sobre a indenização em si, mas, sim, os juros que corrigem essa conta", afirma Sérgio Malta, presidente do conselho de energia elétrica da Firjan. (FSP - Colunas)

(32) Michel Temer segue um pote até aqui de mágoas em relação ao procurador-geral, Rodrigo Janot. Em conversa recente, disse, segundo relatos: "Não vou esquecer, não vou perdoar esse sujeito". (FSP - Colunas)

Dizem os entendidos que derrotas ensinam mais que vitórias. (FSP - Colunas)

Pudemos observar também que, nas seções Equilíbrio e Saúde e Poder, é comum a identificação mais especificada da fonte, como em (34), aumentando ainda mais a qualificação dessa fonte de conhecimento.

(34) "A lógica de cada parlamentar ter o direito de colocar [a verba] onde quiser, geralmente em seu curral eleitoral, é absurda. Desobriga a pelo menos ter de convencer os colegas de que aquilo é importante", diz o doutor em direito público Eduardo Mendonça, professor do Centro Universitário de Brasília. (FSP - Poder)

As ocorrências do tipo 2 de indeterminação [-id, + s] apareceram $75 \%$ em Colunas e $25 \%$ em Poder, sendo empregadas por meio de verbo dicendi e por meio de conectivos, 0 único caso dessa indeterminação parcial de referência em Poder pode ser observado no exemplo (35): 
(35) Funaro é apontado como o operador financeiro do grupo político chamado de "PMDB da Câmara", que, segundo diferentes investigações, atuou na Petrobras e na Caixa Econômica Federal, banco que administra o FI-FGTS. (FSP - Poder)

Nesse exemplo, embora o autor tenha conhecimento sobre essas "diferentes investigações", ele opta por não identificá-las para o leitor, pois não julga essa identificação importante para a argumentação.

A ausência de ocorrências do tipo 1 [+id, -s], que marca um desconhecimento do emissor da identificação da fonte e um possível conhecimento do receptor dessa referência, pode ser explicada por não se tratar de uma interação, uma entrevista, sendo assim, dificilmente o autor colocaria uma informação que estaria disponível para o leitor e não para ele [+id, -s], como acontece em perguntas. O único caso de fonte indefinida foi encontrado em Colunas e trata-se de um caso de identificabilidade desinencial empregado por meio de um verbo dicendi (33) acima.

\section{Considerações finais}

Ainda que a análise aqui empreendida seja parcial, pode-se afirmar que a hipótese de que textos de caráter político e científico recorrem mais às fontes exatas da informação se comprova; como visto na seção anterior, o uso foi predominante nas seções Poder e Equilíbrio e Saúde.

As diferentes formas de expressão da evidencialidade reportativa e citativa comprovam essa diferenciação na língua portuguesa, língua com expressão lexical da categoria. Notamos que o tipo de texto interfere no tipo de reportativo e/ou citativo que será usado, com fonte definida, parcialmente indefinida ou totalmente indefinida, além de interferir no tipo de discurso, mostrando uma diferença argumentativa nos diferentes tipos de expressão.

Nessa primeira análise, embora a diferença quantitativa entre as seções tenha sido mencionada, não foi possível fazer um aprofundamento sobre as razões por que ocorre essa variação; pretendemos, em análise futura, especificar as diferenças e suas motivações.

A maior especificação da fonte, com descrição de titulação do enunciador-fonte, como mostrado no exemplo (34) da seção de análise, parece ser um recurso recorrente para aumentar a credibilidade da informação reportada. Esse recurso será aprofundado em próxima análise, com a inclusão de um critério que possa identificar a ocorrência desse tipo de especificação, além de distinguir as ocorrências apenas em fonte definida, parcialmente indefinida ou indefinida. 


\section{REFERÊNCIAS}

AIKHENVALD, A. Y. Evidentiality. Oxford: Oxford University Press, 2004.

CORNILLIE, B. Evidentiality and epistemic modality in Spanish (semi-)auxiliaries: A cognitivefunctional approach. Berlin/New York: Mouton de Gruyter, 2007.

DALL'AGLIO-HATTNHER, M. M. Evidencialidade e modalidade: forma e função. São Paulo: FAPESP, 2001. (Relatório de pesquisa)

DE HAAN, F. Evidentiality and epistemic modality: setting boundaries. Southwest Journal of Linguistics, v. 18, p. 83-101, 1999.

FOSSEY, M. F. A semântica global em duas revistas de Divulgação científica: Pesquisa Fapesp e Superinteressante. 2006. Dissertação (Mestrado em Linguística) - Instituto de Estudos da Linguagem, Universidade Estadual de Campinas, Campinas, 2006.

HENGEVELD, K.; DALL'AGLIO-HATTNHER, M. M. Four types of evidentiality in the native languages of Brazil. Linguistics, v. 53, n. 3, p. 479-524, 2015.

HENGEVELD, K.; FISCHER, R. A'ingae (Cofán/Kofán) Operators. Open Linguistics, 4, p. 328-355, 2018.

HENGEVELD, K.; MACKENZIE, L. Functional Discourse Grammar: A typologically-based theory of language structure. Oxford: Oxford University Press, 2008.

MARTINS, N. S. A. Introdução à estilística: a expressividade na língua portuguesa. São Paulo: T. A. Queiroz, 1989.

RENDÓN, J. G. Interpersonal Aspects of Evidentiality in Ecuadorian Quechua. Working Papers, Amsterdã: ACLC 1, p. 37-50, 2006.

SQUARTINI, M. Lexical vs. Gramatical evidentiality in French and Italian. Linguistics, v. 46-5, p. 917-947, 2008.

TEIXEIRA, M. L. S. A indeterminação pragmática e semântica do sujeito. 2014. Tese (Doutorado em Estudos Linguísticos) - Instituto de Biociências, Letras e Ciências Exatas, Universidade Estadual Paulista "Júlio de Mesquita Filho", São José do Rio Preto, 2014.

WILLET, T. A cross-linguistic survey of the grammaticalization of evidentiality. Studies in Language, v. 12, n. 1, p. 51-97, 1988. 